\title{
Historein
}

Vol 14, No 1 (2014)

On the Edge of History and Philosophy

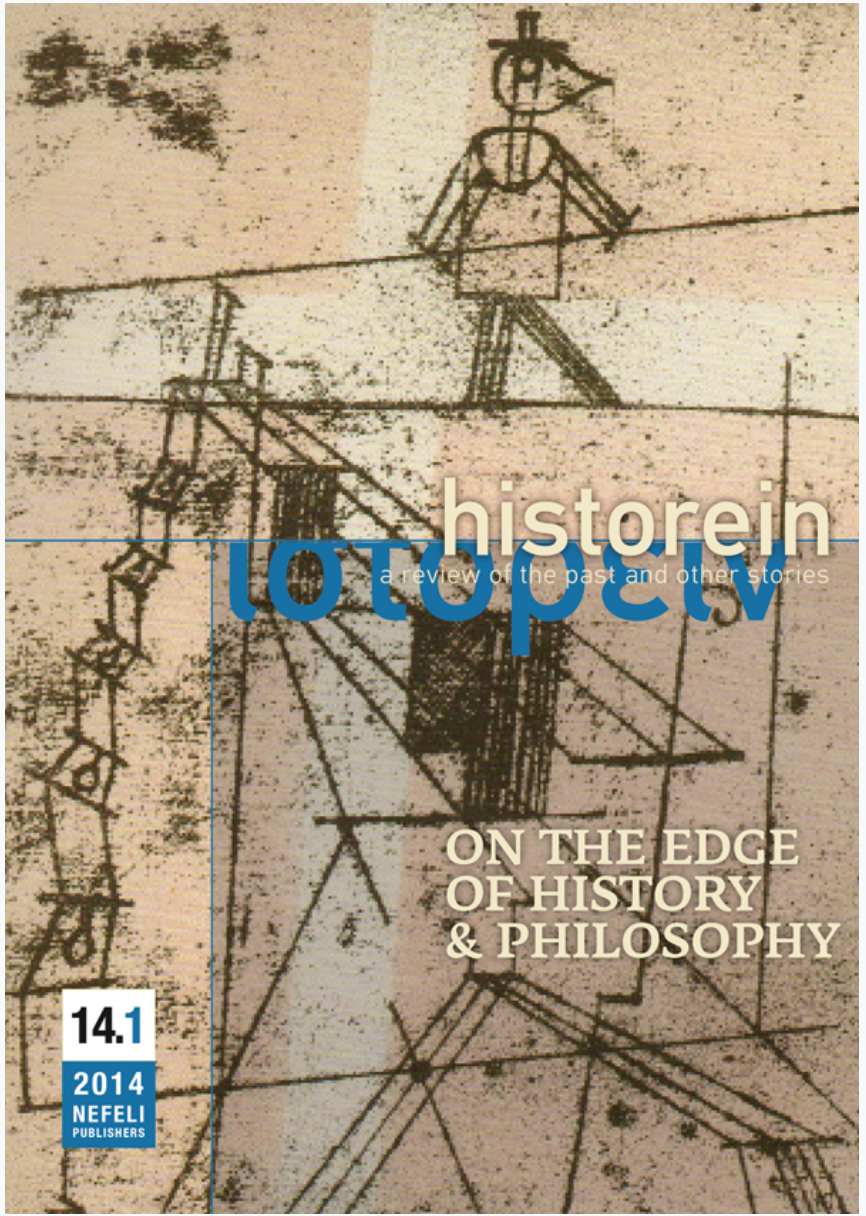

\section{Chris Lorenz's idea of conceptual inversion}

Ewa Domanska

doi: $10.12681 /$ historein.214

Copyright $\odot$ 2014, Ewa Domanska

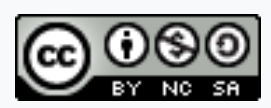

This work is licensed under a Creative Commons Attribution-NonCommercialShareAlike 4.0.

\section{To cite this article:}

Domanska, E. (2013). Chris Lorenz's idea of conceptual inversion. Historein, 14(1), 93-94.

https://doi.org/10.12681/historein.214 
In the following text I will focus on Chris Lorenz's ideas which, from my point of view, present a valuable contribution to the discussion about the contemporary condition of theory in the human and social sciences in general. I find particularly thought-provoking Lorenz's idea of "conceptual inversion", presented in the article "'Won't you tell me where have all the good times gone?' On the advantages and disadvantages of modernization theory for history". Lorenz summarises his view in the following way:

[T]he problems associated with the history of society are the consequence of conceptual inversion. What historians of society basically did was invert the "traditional" positions they criticized (on the model of Marx's inversion of Hegel). As a result, the problems pertaining to the positions criticized were not resolved but only turned on their head. The "traditional" focus on individuals was inverted into a "modern" focus on structures, the "traditional' focus on culture was inverted into a "modern" focus on structures, and "traditional" emphatic understanding was inverted into "modern" causal explanation. It is argued that in order to escape from the conceptual trap of inversion new theoretical labour by historians of society will be necessary ... I would like to designate this "negative" defining reference to other paradigms as the reciprocal "negative bond" of scientific programmes. In science this "negative bond" is politically unavoidable, as it fulfils strategic functions in scientific controversies. Just as in the "political field" so in the "scientific field": there is no struggle without a strategy. Epistemologically - that means cognitively a "negative bond", however, also brings important negative consequences with it in the

\section{Chris Lorenz's}

\section{idea of conceptual}

\section{inversion}

\section{Ewa Domańska}

Adam Mickiewicz University, Poznań 
long term. This is because the methodological and theoretical views of scientific programmes to a certain extent embody negations, i.e. "inversions" of the views being criticized by them. And because in inversions the fundamental conceptual structure of that which has been inverted remains the same (just as the teleological structure of history in Hegel's idealism survived in its materialistic "inversion" by Marx), many of the conceptual problems connected with the criticized positions survive in this way. As a result they can develop into permanent "epistemological blockades" demanding new theoretical effort to overcome them. Again, the teleology in Marx's conception of history deriving from the inversion of Hegel is a clear case in point.

My first question is as follows: Lorenz's understanding of a scientific programme seems similar to Imre Lakatos' conception of scientific research programmes. Thus, what is the relation between Lorenz's idea of conceptual inversion and Lakatos' idea of reconfigurations of research programmes $?^{2}$ How can Lorenz reconcile these two ideas, and how might the idea of intellectual inversion be helpful for transcending Lakatos' understanding of the phenomenon of "paradigm changes" in the humanities, or - vice versa - how might Lakatos enrich his view of intellectual inversion as an explanation of this phenomenon?

The second question refers to Lorenz's and my common interest in empiricism, however differently understood. Lorenz identifies empiricism as "positivism of facts" ("positivism with a small p" while "Positivism with a capital P is the covering-law view of explanation"). The idea of "conceptual inversion" allows Lorenz to define narrativism as inverted positivism (thus, as an inversion of the "positivism of facts"). ${ }^{3}$ My approach is related to the so-called new empiricism and new materialism. The first one, popular especially in sociology, derives from a theory of Gilles Deleuze and focuses on rethinking the connection between theoretical and empirical research and methods in the study of reality. The new materialism calls for rethinking the traditional (Cartesian) concept of matter as passive, which - as it is declared - is needed because of biotechnological progress and recent attempts to break away from the western tradition of anthropocentrism with its reductionist concept of matter as empty, lifeless and lacking agency. ${ }^{I}$ wonder if Lorenz sees any common ground on which his ideas, which emerge out of a criticism of narrativism, and mine, which are located in emerging paradigm of posthumanities, could meet?

\section{NOTES}

1 Chris Lorenz, “'Won't you tell me where have all the good times gone?' On the advantages and disadvantages of modernization theory for history", Rethinking History 10/2 (2006): 171-172 and 182.

2 Imre Lakatos, The Methodology of the Scientific Research Programmes (Philosophical Papers, vol. 1) eds John Worrall and Gregory Currie, Cambridge: Cambridge University Press, 1978.

3 Chris Lorenz, "Can histories be true? Narrativism, positivism and the 'metaphorical turn'”, History and Theory 37/3 (1998): 309-329. In this article, Lorenz writes: "The subjectivistic drift of metaphorical narrative philosophy can be explained by its reversal of the two brands of positivism ..., the positivism of facts and the positivism of covering-law explanation. As both forms of positivism were derived from the dominant image of natural science, metaphorical narrativism owes its fundamental characteristics to its reversal of the nineteenth-century natural science model" (324).

4 Nicholas Gane, “Concepts and the 'new' empiricism”, European Journal of Social Theory 12/1 (2009): 83-97; Diana H. Coole and Samantha Frost (eds), New Materialisms: Ontology, Agency, and Politics, Durham/London: Duke University Press, 2010. 